3D-моделюванням проведена оптимізація параметрів відцентрової сокодавки з кульовим автобалансиром при імпульсній зміні незрівноваженості сита. Показана ефективність раніше запропонованої методики оптимізації. Підтверджено, що збільщення кількості куль в автобалансирі та зменшення радіусу бігової доріжки куль пришвидшує настання автобалансування. Виявлена неефективність використання двохкульових автобалансирів для дослідження тривалості перехідних процесів при автобалансуванні роторних машин

Ключові слова: кульовий автобалансир, автобалансування, 3D-моделювання, імпульсна зміна незрівноваженості, перехідні процеси, відцентрова сокодавка

3D-моделированием проведена оптимизация параметров центробежной соковыжималки с шаровым автобалансиром при импульсном изменении неуравновешенности сита. Показана работоспособность ранее предложенной методики оптимизации. Подтверждено, ито увеличение количества шаров 6 автобалансире и уменьшение радиуса беговой дорожки шаров ускоряет наступление автобалансировки. Выявлена неэффективность использования двухшаровых автобалансиров для исследования продолжительности переходных процессов при автобалансировке роторных машин

Ключевые слова: шаровой автобалансир, автобалансировка, 3D-моделирование, импульсное изменение неуравновешенности, переходные процессы, центробежсная соковижималка
UDC $62-752+62-755: 641.514 .7$

DOI: $10.15587 / 1729-4061.2017 .102241$

\section{PARAMETER OPTIMIZATION OF THE CENTRIFUGAL JUICER WITH THE BALL AUTO- BALANCER UNDER THE IMPULSE CHANGE OF AN UNBALANCE BY 3D MODELING}

\author{
V. Goncharov \\ $\mathrm{PhD}$, Associate Professor \\ Department of Mathematics and Physics** \\ E-mail: honchv@ukr.net \\ K. Du m e n k o
}

Doctor of Technical Sciences, Associate Professor Department of Operation and Repair of Machines**

E-mail: dumenkokm@gmail.com

A. Nevd a k h a

$\mathrm{PhD*}$

E-mail: aunevdaha@ukr.net

V. P i r o g o v

$\mathrm{PhD*}$

E-mail: vladimir-pirogovvv@rambler.ru *Department of Machine Parts and

Applied Mechanics**

**Central Ukrainian National Technical University Univerytetskyi ave., 8, Kropivnitskiy, Ukraine, 25006

\section{Introduction}

There are unbalances during the operation of many rotor machines and as a consequence, there are vibrations of the case of the machine. The rotors of such machines should be balanced on the move by passive auto-balancers [1-3].

In the process of developing the passive auto-balancers for balancing of rotors of specific machines, the following problems are investigated (theoretically or by computer modeling):

- the principal possibility of balancing of a specific rotor by passive auto-balancers of any [3-7] or certain [3, 8-18] type;

- the possibility of improvement of the accuracy of balancing and reduction of residual vibrations [2, 19-22, 25];

- the possibility of acceleration of the auto-balancing onset [3, 23-27].

After this, the process of rotor balancing by the passive auto-balancer is experimentally investigated, in particular, the quality of balancing is evaluated [28, 29].

Research of the transition processes, which occur during auto-balancing, is the most difficult. Analytically, these processes have been studied in the few works [3, 13, 14, 17, 18].
This is due to the complexity of the differential equations, describing the motion of rotor systems with auto-balancers [3, 8-18]. Alternative methods of research are the numerical experiment and 3D modeling [9-11, 14-16, 25-27].

Centrifugal machines can be conditionally divided into those, in which the unbalance changes:

- slowly (CD/DVD drives, drums of washing machines, extractors, centrifuges, separators, fan impellers, aircraft engine rotors, etc.);

- fast, impulsively (centrifugal crushers, hand grinders, centrifugal juicers, drums of some extractors, etc.).

To date, centrifugal machines, in which the unbalance varies slowly, have been more investigated [25-29]. Therefore, it is important to study the process of auto-balancing of rotor machines under the impulse change of the unbalance by $3 \mathrm{D}$ modeling.

\section{Literature review and problem statement}

The designs and operating principle of classical ball, pendulum, roller, ring auto-balancers have been described 
in [1, 2]. In this, in [1] auto-balancers, designed for balancing drums of washing machines, and in [2] auto-balancers for balancing various fast-rotating rotors have been described. The most complete history of passive auto-balancers, the operating principle of auto-balancers, the scope of their application have been described in [3]. The designs of non-classical auto-balancers have been also described. In these designs, the auto-balancers of special shape can rotate in a certain way around a point on the longitudinal axis of the rotor.

The principal possibility of automatic balancing of various rotating bodies by passive auto-balancers of any type has been studied in [3-7] for:

- the rigid rotor, balanced by one auto-balancer and performing plane, spherical or spatial motion [3];

- isolated rotating bodies (artificial satellites of the Earth, or space vehicles, whose position in space is stabilized by rotation) [4];

- the rotor with a fixed point and an elastic support [5];

- the two-support rotor, which implements spatial motion $[6]$;

- the rotor with an impeller, on which aerodynamic forces act [7].

The empirical criterion for the stability of the main motion [4] or the empirical criterion for the auto-balancing onset $[5,6]$ has been used in investigations. The criteria are the most effective methods for determining the conditions, under which auto-balancers of any type and in any number can balance the flexible or rigid rotor on certain supports.

The conditions for the auto-balancing onset during balancing rigid rotors by passive auto-balancers of a certain type have been determined:

- for a two-ball auto-balancer in the framework of the flat rotor model, the rotor model with a fixed point, the rotor model on two elastic supports [8];

- for classical and non-classical auto-balancers in the framework of rotor models, in which auto-balancers move in a plane-parallel manner [3];

- during balancing of the rigid rotor on two isotropic elastic supports statically by one two-ball auto-balancer [9] and dynamically by two two-ball auto-balancers [10];

- during dynamic balancing of the rigid rotor on two anisotropic elastic supports by two two-ball auto-balancers [11];

- during the static balancing of the rigid rotor, placed in a heavy elastic-viscous-fixed case with a small [12] and a large mass of an auto-balancer [13] by a single multi-ball auto-balancer.

The conditions for the auto-balancing onset during balancing of flexible rotors by passive auto-balancers of a certain type have been determined:

- in case of balancing of the massive two-support flexible rotor by one and two two-ball auto-balancers [14];

- during balancing of the unbalanced disk, mounted on the flexible weightless two-support shaft by one [15] or two [16] two-ball auto-balancers, when auto-balancers are mounted on the shaft at a distance from the disk;

- during balancing of the massive flexible rotor on two elastic-viscous supports by two multi-ball auto-balancers, mounted on the shaft near the supports [16];

- during the dynamic balancing of the flexible massive rotor on two compliant supports by two passive auto-balancers, located near the supports, also in [17], the conditions for the auto-balancing onset have been determined, and in [18], transition processes have been investigated.
The influence of various factors on the balancing accuracy has been investigated in [19-22].

In [19], it has been shown that the main reasons for the decrease of the accuracy of the rotor balancing by passive auto-balancers are the eccentricity of the running track, the rolling resistance forces of correction weights along the track, external vibrations, and it has been shown that the less the eccentricity and the dry friction forces, the less the error of balancing.

In [20], the effect of rolling resistance forces of correction weights on the accuracy of the rotor balancing by ball auto-balancers has been estimated, and it has been suggested to reduce the rolling resistance forces of the balls by increasing the radius of correction weights.

In [21], it has been shown that small external disturbing forces can excite oscillations of the balls in the vicinity of the auto-balancing position, thus affecting the auto-balancing quality.

In [22], the balancing accuracy has been studied with allowance for the dry friction forces and shocks between the correction weights.

It should be noted that the transition processes, after which an auto-balancing occurs, have been also analytically investigated in [3, 12, 14, 18, 21].

In [23], the parameters of ball (roller) auto-balancers have been proposed, at which the auto-balancer has the largest balancing capacity in a limited volume and which ensure the fastest auto-balancing onset. It has been shown; that the largest correcting weights, placed in the auto-balancer, create the largest balancing capacity. It has been established; that the auto-balancing onset is accelerated with the greater number of correction weights.

So, the works [3-23] allow us to conclude whether it is possible in principle to balance a certain rotor by passive auto-balancers; how to improve the quality of auto-balancing; how to accelerate the auto-balancing onset. Let's consider this on the example of the centrifugal juicer.

The rotor of the centrifugal juicer carries out spatial motion. The principal possibility of static balancing of such a rotor by an auto-balancer of any type has been proved in [3]. Taking this into account, technical solutions for the modernization of the centrifugal juicer with the cylindrical sieve, with both manual and semi-automatic ejection of pulp, for static sieve balancing by one auto-balancer have been proposed in [24]. In the work [12], the process of balancing such a rotor by the multi-ball auto-balancer has been theoretically studied, and transition processes have been investigated.

In [23], general recommendations for increasing the accuracy of the auto-balancing onset and reducing the duration of transition processes have been given. These recommendations are applicable to the centrifugal juicer.

In [25], it has been established that it is expedient to estimate the rotor machine operation with auto-balancers based on residual unbalances and the duration of transition processes; methods for optimizing the parameters of the ball auto-balancer for minimizing the operation quality functional of the rotor machine with an auto-balancer have been proposed. In [26], methods of selecting statistically suitable regression functions, when the duration of transition processes is the quality functional have been proposed. Using the proposed [25, 26] methods and by $3 \mathrm{D}$ modeling, the parameter optimization of the auto-balancer that statically balances a centrifugal juicer at its run-up and constant unbalance on the example of minimization of residual vibration 
accelerations [25] and the duration of transition processes [26] has beencarried out. In this, it has been found that without the parameter optimization of the centrifugal juicer and auto-balancer, the value of residual vibration accelerations can exceed the smallest possible value by $30 \%$, and the duration of transition processes - by ten times.

The conducted studies are not completed for the following two reasons. First, the unbalance of the centrifugal juicer varies impulsively, and studies for the parameter optimization of a centrifugal juicer and auto-balancer under such a change of an unbalance have not been carried out. Secondly, experimental studies have not been completed.

So, it is relevant to optimize the parameters of the centrifugal juicer with the ball auto-balancer under the impulse change of an unbalance at cruising velocity of the rotor using 3D modeling.

It should be noted, that unlike the centrifugal juicer, studies for axial fans are logically completed. So, in the work [27], the parameters of the axial fan and two-ball auto-balancers that balance the centrifugal juicer have been optimized by 3D modeling. In [28], the efficiency of dynamic balancing of an impeller of the axial fan by two-ball auto-balancers has been experimentally determined. And in the work [29], the efficiency of static and dynamic auto-balancing of an impeller of the axial fan by one and two ball auto-balancers has been experimentally investigated, vibratory accelerations on the run-up, cruising and run-out sections of the impeller have been estimated.

\section{The purpose and objectives of the study}

The purpose of the work is to study the process of auto-balancing of rotor machines with ball auto-balancers under the impulse change of a rotor unbalance at cruising velocity by $3 \mathrm{D}$ modeling.

To achieve this purpose, it is necessary to solve the following research problems:

- to develop the most unfavorable laws of the impulse change of the sieve unbalance;

- to test the efficiency of the previously developed methods (of optimizing the parameters of the centrifugal juicer to minimize the duration of transition processes under run-up of the centrifugal juicer with the fixed initial unbalance) under the impulse change of an unbalance at cruising velocity;

- to investigate the influence of the auto-balancer parameters on the duration of the transition processes and to test the previously obtained theoretical results, concerning the influence of the number of correction weights in an auto-balancer and the radius of the auto-balancer running track on the duration of the transition processes;

- to compare the results of optimizing the parameters of an auto-balancer and the centrifugal juicer, obtained under run-up, with the parameters, obtained under the impulse change of an unbalance.

\section{Methods of researching the transition processes under the impulse change of an unbalance}

\subsubsection{D model for conducting the experiments}

Modeling is actual for the centrifugal juicers with a cylindrical sieve, with both manual (Fig. 1,a), and semi-automatic (Fig. 1, $b$ ) ejection of pulp.

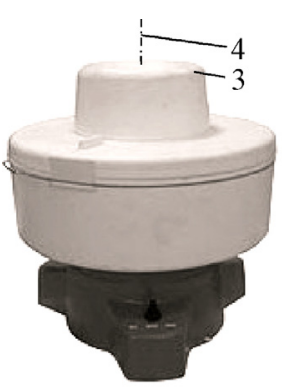

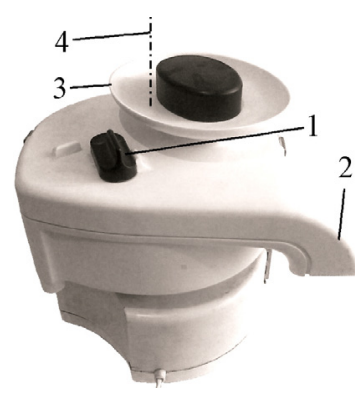

$b$
Fig. 1. Photographs of the centrifugal juicers:

$a-$ with manual ejection of pulp, $b-$ with semi-automatic ejection of pulp; 1 - the device for ejection of pulp;

2 - the hole for the exit of pulp; 3 - the tray for feeding of raw materials; 4 - the axis of the sieve rotation

In Fig. 2, using the centrifugal juicer "Rodnichok" (Ukraine) as an example, the main units and parts of centrifugal juicers are shown.

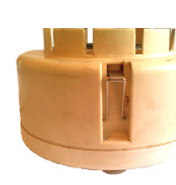

a

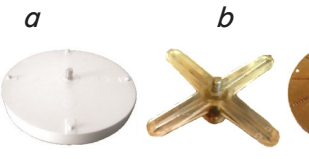

e

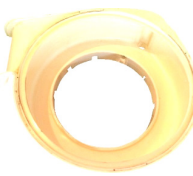

$$
f
$$

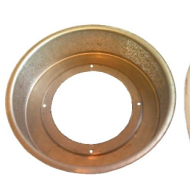

c

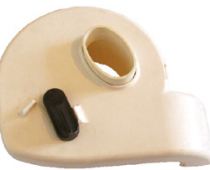

Fig. 2. Photographs of the main units and parts of the centrifugal juicer with semi-automatic ejection of pulp:

$a$ - the case with the drive; $b$ - the lower cover; $c-$ the sieve; $d-$ the upper cover; $e, f-$ the platform in the form of a disk $(e)$ or cross $(f) ; g$ - the disk-grater; $h-$ the tray; $i-$ the pusher of raw materials

Modernization of the centrifugal juicer [24] consists in planting the platform, combined with the ball auto-balancer (Fig. 3, $b$ ), instead of the platform in the form of a disk or cross (Fig. 2,e,f) on the rotor shaft (Fig. 3,a).

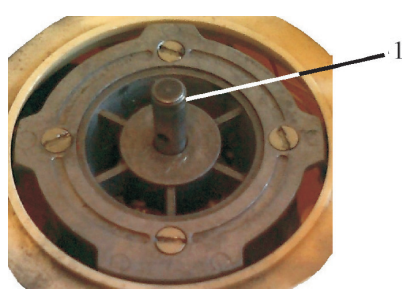

a

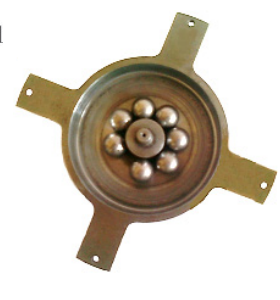

$b$
Fig. 3. Modernization of the centrifugal juicer: $a-$ the drive; $b-$ the platform, combined with the ball auto-balancer; 1 - the drive shaft

In $[25,26]$, the 3D model of the modernized centrifugal juicer has been created in the Solid Works computer-aided design system using the Cosmos Motion module.

It is the model that is used for conducting virtual experiments. 


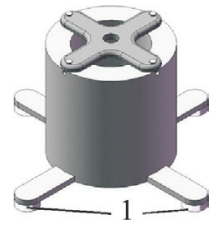

$a$

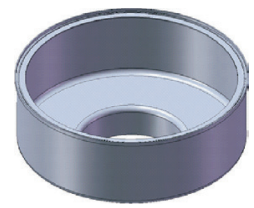

$b$

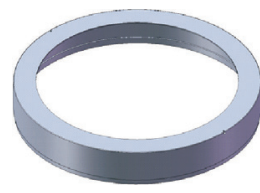

c

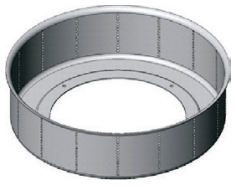

$d$

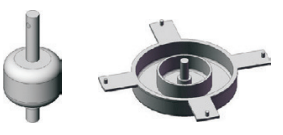

e

$f$
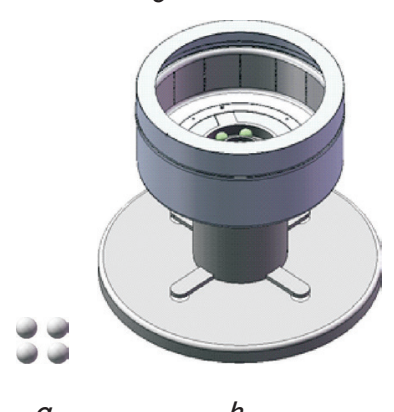

$h$

Fig. 4. Computer 3D models of the main units and parts of the modernized centrifugal juicer and the 3D model of the juicer in assembled shape: $a-$ the drive case; $b, c$ - lower and upper covers; $d$ - the sieve; $e-$ the rotor; $f$ - the auto-balancer case; $g-$ the balls; $h-3 \mathrm{D}$ model in assembled shape; $1-$ supports

\section{2. Methods of conducting the experiments}

The methods, proposed in $[25,26]$ and that takes into account the operation features of rotor machines with an auto-balancer are used in the experiments and analysis of the obtained results. The methods use the theory of multifactor experiments and include:

- description of a "black box" [25];

- methods of selecting a statistically suitable regression function [26];

- planning and conducting a multifactor experiment [25];

- study of the obtained results using the STATISTICA software package for statistical analysis of data and the MathCad computer algebra system [25].

Main assumptions, simplifications, hypotheses. The pressed mass of the processed raw materials forms a predominantly static unbalance on the sieve. The moment unbalance is small and it can be neglected. It is assumed in modeling; that the plane of the static unbalance is equidistant from the upper and lower sieve edges. The ball auto-balancer is under the sieve. Therefore, the distance between the plane of the static unbalance and the correction plane is $35 \mathrm{~mm}$.

In the most unfavorable for auto-balancing cases, the sieve unbalance changes impulsively; in a short time $\Delta t$. It is assumed that a decrease of the duration of the auto-balancing onset; after a change of the unbalance leads to a decrease of the average vibration characteristics (mean square movements, velocities, accelerations). Therefore, the optimization is carried out according to the duration of the auto-balancing onset (the duration of transition processes) at cruising velocity of the sieve rotation.

In all experiments, the balancing capacity of an auto-balancer is the same and equals to $\mathrm{S}_{\mathrm{AB}}=977.88 \mathrm{~g} \mathrm{~mm}$.

Modeling the impulse change of an unbalance. The force from the static unbalance is modeled in the Cosmos Motion module using the "Action Only" instrument.

The vectors of the forces lie in plane, equidistant from the upper and lower sieve edges. The forces, applied to the sieve are perpendicular to the axis of rotation and directed away from it.
In the experiments, the forces are given three different discrete values: small $(15 \mathrm{~N})$, medium $(70 \mathrm{~N})$ and large $(96 \mathrm{~N})$. To balance these forces, $16 \%, 73 \%$ and $100 \%$ of the balancing capacity of the auto-balancer, respectively, are used. In this, the balls in a two-ball auto-balancer diverge by $163^{\circ}$, $90^{\circ}$ and $30^{\circ}$, respectively.

The modeling process of the impulse change of unbalances is shown in Fig. 5.

Fig. 5 shows the following time intervals:

$\left[0 ; t_{1}\right)-$ the sieve is accelerated to the cruising rotation velocity;

$\left[\mathrm{t}_{1} ; \mathrm{t}_{1}+\Delta \mathrm{t}\right)$ - the force $\mathrm{F}_{1}$ is "on", $\Delta \mathrm{t}=0.05 \mathrm{~s}$;

$\left[\mathrm{t}_{1} ; \mathrm{t}_{2}\right)$ - auto-balancing onset is ensured and the balls come to the first auto-balancing position;

$\left[t_{2} ; t_{2}+\Delta t\right)-t h e$ force $F_{1}$ is "off" and the force $F_{2}$ is "on";

$\left[\mathrm{t}_{2} ; \mathrm{T}\right)$ - auto-balancing onset is ensured and the balls come to the second auto-balancing position.

The duration of transition processes is estimated at the most unfavorable changes of an unbalance, that is, when the balls (in a two-ball auto-balancer) must implement the greatest angular movement along the running track for coming to the auto-balancing position.

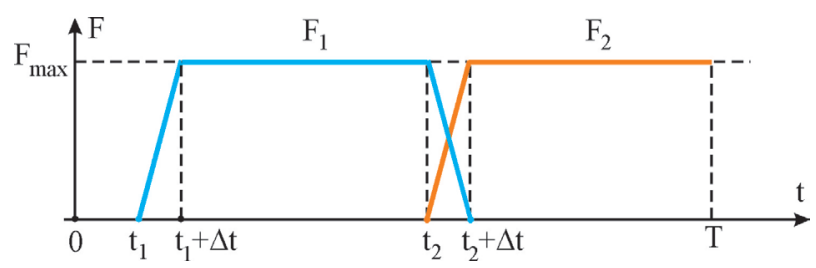

Fig. 5. Modeling of the impulse change of the sieve unbalance

Methods for determining the time of the auto-balancing onset. The time of the auto-balancing onset is counted from the time $t_{2}$. To determine the moment of the auto-balancing onset, a vibration diagram of the instantaneous value of the vibration accelerations module of the point of intersection of the rotation axis with the horizontal surface of the upper cover of the centrifugal juicer is used [25]. As the auto-balancing onset moment of time, the moment is taken, from which the vibration acceleration diagram falls in the band $\left[\mathrm{a}_{\mathrm{st}}-\Delta \mathrm{a} ; \mathrm{a}_{\mathrm{st}}+\Delta \mathrm{a}\right]$, where $\mathrm{a}_{\mathrm{st}}$ is the vibration acceleration on the steady motion, $\Delta \mathrm{a}$ is the half-width of the band. For all experiments, $\Delta \mathrm{a}=5 \mathrm{~mm} / \mathrm{s}^{2}$.

During the experiments, fixed values are given to a part of the mass-inertia parameters of the centrifugal juicer, and the duration of transition processes is minimized with another part of the parameters.

Within each multifactor experiment:

- fixed values are given to the balancing capacity $\left(\mathrm{S}_{\mathrm{AB}}\right)$ of the auto-balancer, the radius $(\mathrm{R})$ of the balls running track, the number (n) and the radius (r) of the balls in the auto-balancer;

- minimization is carried out using the coefficients of elastic forces $\left(\mathrm{k}_{\mathrm{o}}\right)$ and viscosity $\left(\mathrm{b}_{\mathrm{o}}\right)$ of the supports, the viscous resistance to the relative motion of the balls $\left(b_{b}\right)$.

When optimizing the parameters of the centrifugal juicer, first a regression function is found in the form [26]:

$$
\mathrm{t}_{\mathrm{tr}}+\ln ^{3}\left(\mathrm{t}_{\mathrm{tr}}-\Delta \mathrm{t}\right)=\mathrm{c}_{0}+\sum_{\mathrm{i}=1}^{\mathrm{m}} \mathrm{c}_{\mathrm{i}} \tilde{\mathrm{v}}_{\mathrm{i}}+\sum_{\mathrm{i}=1}^{\mathrm{m}-1} \sum_{\mathrm{j}=\mathrm{i}+1}^{\mathrm{m}} \mathrm{c}_{\mathrm{ij}} \tilde{\mathrm{v}}_{\mathrm{i}} \tilde{\mathrm{v}}_{\mathrm{j}}+\sum_{\mathrm{i}=1}^{\mathrm{m}} \mathrm{c}_{\mathrm{ii}} \tilde{\mathrm{v}}_{\mathrm{i}}^{2},
$$


where $\tilde{\mathrm{v}}_{1}, \tilde{\mathrm{v}}_{2}, \ldots, \tilde{\mathrm{v}}_{\mathrm{m}}$ are the dimensionless control factors; $\mathrm{c}_{0}$ is the free regression term; $c_{i}, c_{i j}, \quad / i, j=1, m, j>i /$ are coefficients of regression.

In [26], the function (1) has been determined as the most suitable for determining the duration of transition processes during balancing the centrifugal juicer at its run-up with the fixed initial unbalance.

As controlling factors, the parameters $\mathrm{k}_{\mathrm{o}}, \mathrm{b}_{\mathrm{o}}, \mathrm{b}_{\mathrm{b}}$ are chosen. In this, the block diagram of the "black box" has the form, shown in Fig. 6.

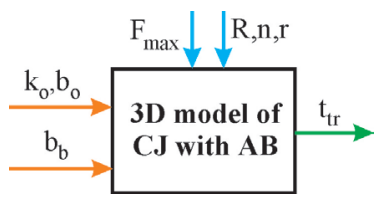

Fig. 6 . The block diagram of the "black box" for the search of the optimal parameters of the 3D model of the centrifugal juicer with the auto-balancer

The area of change of the control factors is chosen the same as in [25]:

$-\mathrm{k}_{0} \in[1 ; 3] \mathrm{N} / \mathrm{mm}$ : at starting under the presence of the sieve unbalance, the case of the centrifugal juicer at $\mathrm{k}_{\mathrm{o}}<1 \mathrm{~N} / \mathrm{mm}$ deviates significantly from the equilibrium position, and at $\mathrm{k}_{\mathrm{o}}>$ $>3 \mathrm{~N} / \mathrm{mm}$ "breaks" off the supports;

$-\mathrm{b}_{0} \in[0.005 ; 0.045] \mathrm{N} \mathrm{s} / \mathrm{mm}:$ at $\mathrm{b}_{0}<0.005 \mathrm{~N} \mathrm{~s} / \mathrm{mm}$, the case vibrations of the centrifugal juicer fade out for a very long time; at $b_{0}>0.045 \mathrm{~N} \mathrm{~s} / \mathrm{mm}$, the case of the centrifugal juicer almost does not vibrate and moves slowly to the equilibrium position;

$-b_{b} \in\left[510^{-5} ; 1.510^{-3}\right] \mathrm{N} \mathrm{s} / \mathrm{mm}:$ at $b_{b}<510^{-5} \mathrm{~N} \mathrm{~s} / \mathrm{mm}$, the balls "pursue" the rotor for a long time during the run-up; at $\mathrm{b}_{\mathrm{b}}>1.510^{-3} \mathrm{~N} \mathrm{~s} / \mathrm{mm}$, the balls go to the balancing positions for a long time.

The values of the factors in the dimensional $\left(\mathrm{k}_{\mathrm{o}}, \mathrm{b}_{\mathrm{o}}, \mathrm{b}_{\mathrm{b}}\right)$ and dimensionless $\left(\tilde{\mathrm{k}}_{0}, \tilde{\mathrm{b}}_{\mathrm{o}}, \tilde{\mathrm{b}}_{\mathrm{b}}\right)$ forms for the three-level experiment are given in Table 1.

Table 1

The values of control factors in dimensional and dimensionless forms

\begin{tabular}{|c|c|c|c|c|c|}
\hline \multirow{2}{*}{ No. } & \multirow{2}{*}{ Level } & $\mathrm{k}_{\mathrm{o}}$ & $\mathrm{b}_{\mathrm{o}}$ & $\mathrm{b}_{\mathrm{b}}$ & $\tilde{\mathrm{k}}_{\mathrm{o}}, \tilde{\mathrm{b}}_{\mathrm{o}}, \tilde{\mathrm{b}}_{\mathrm{b}}$ \\
\cline { 3 - 6 } & & $\mathrm{N} / \mathrm{mm}$ & $\mathrm{N} \mathrm{s} / \mathrm{mm}$ & $\mathrm{N} \mathrm{s} / \mathrm{mm}$ & - \\
\hline 1 & lower & 1 & 0.005 & $5 \cdot 10^{-5}$ & -1 \\
\hline 2 & average & 2 & 0.025 & $5,75 \cdot 10^{-4}$ & 0 \\
\hline 3 & upper & 3 & 0.045 & $1,5 \cdot 10^{-3}$ & 1 \\
\hline
\end{tabular}

For carrying out multifactor experiments, a two-block Box-Behnken design is used for 3 factors and three levels. In each multifactor experiment, 13 virtual experiments are performed at certain values of the control factors.

Statistical analysis of the regression model (1) for each multifactor experiment is performed using the STATISTICA 6 software package similarly to [25-27]. In this, two main indicators are used:

- Student's criterion (t-criterion) for determining the statistical significance of the regression coefficients;
- Fisher's criterion (F-criterion) for estimating the statistical reliability of the obtained (initial or simplified) regression equation.

The obtained regression models were investigated for the minimal value of the functional $t_{\mathrm{tr}}$ in the domain of the change of the control factors in the MathCad 15 computer algebra system.

4. 3. Types of experiments, conducted on the 3D model of the centrifugal juicer

There are two types of experiments.

Experiment 1. The efficiency of the methods, proposed in $[25,26]$, is checked for the case of the impulse change of an unbalance at cruising velocity. The influence of the number of the balls $\mathrm{n}$ on the duration of transition processes at the fixed radius of the balls $(\mathrm{r}=8.5 \mathrm{~mm}$ is the maximum structurally permissible value) is investigated.

In this:

a) the number of the balls equals to $n=2 ; 3 ; 4$ pcs.;

b) the radius of a running track is chosen to ensure that the balancing capacity of an auto-balancer remains unchanged and equals to $R=f\left(n, r, S_{A B}\right)$ [23].

Experiment 2. The effect of the radius of the auto-balancer running track on the duration of transition processes with a fixed number $n$ of the balls in the auto-balancer is investigated: $\mathrm{n}=4$.

In this:

a) the radius of the running track is equal to $R=31.86$, $41.60,51.34 \mathrm{~mm}$ in turn;

b) the radius of the balls is chosen so as to ensure the invariance of the balancing capacity of an auto-balancer, that is $r=f\left(n, R, S_{A B}\right)$ [23].

Some additional information about the experimental methods is given in the presentation of the experimental results.

\section{The results of the parameter optimization of} the centrifugal juicer with an auto-balancer under the impulse change of an unbalance by $3 \mathrm{D}$ modeling

5. 1. Identification of unfavorable cases of a change of the sieve unbalance

The classification of the most unfavorable (in terms of the duration oftransition processes) changes of the sieve unbalances is carried out using the example of a two-ball auto-balancer. Such changes of an unbalance are selected, after which the balls must move the greatest distance to the new auto-balancing position.

In Fig. 7, the most unfavorable changes of the small, medium and large unbalances of the sieve and the corresponding relative distances of the balls are shown.

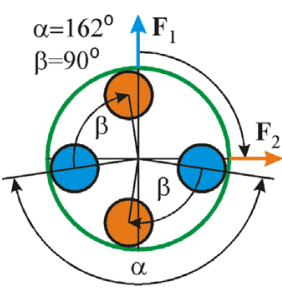

$a$

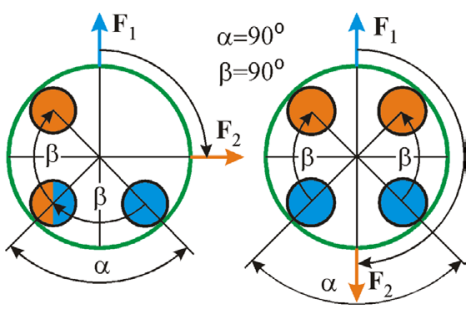

$b$

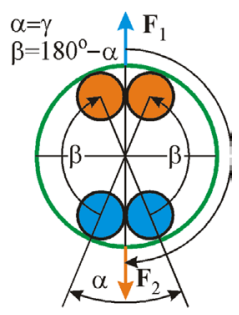

c
Fig. 7. The most unfavorable change of the sieve unbalance: $a$ - small; $b$ - medium; $c$ - large 
In the experiments, the small and medium unbalances turned by $90^{\circ}$, and a large unbalance turned by $180^{\circ}$.

\section{2. Investigation of the influence of the number of} the balls in an auto-balancer on the duration of transition processes (experiment 1)

For experiment 1, three auto-balancers are designed, with radiuses of the running track $\mathrm{R}=41.6 \mathrm{~mm}, \mathrm{R}=33.65 \mathrm{~mm}$, $\mathrm{R}=31.86 \mathrm{~mm}$, respectively. The own multifactor experiment is conducted for each pair of the parameter values $\left(\mathrm{F}_{\max }, \mathrm{n}\right)$ (9 in total). In each of them, 13 experiments were carried out. Table 2 shows the results of optimization that are the smallest values of the duration of transition processes and the values of the control factors, under which these values are obtained. The results of the virtual experiments and statistical analysis are not given; because of their cumbersomeness.

Table 2

The results of optimization of the duration of transition processes with a fixed radius of the balls and the balancing capacity of an auto-balancer

\begin{tabular}{|c|c|c|c|c|c|c|c|c|c|c|}
\hline \multirow{4}{*}{ No. } & \multirow{4}{*}{$\mathrm{F}_{\max }, \mathrm{N}$} & \multicolumn{9}{|c|}{$\mathrm{n}$, pcs. } \\
\hline & & \multicolumn{3}{|c|}{2} & \multicolumn{3}{|c|}{3} & \multicolumn{3}{|c|}{4} \\
\hline & & \multirow[b]{2}{*}{$\mathrm{t}_{\mathrm{tr}}, \mathrm{s}$} & $b_{o}$ & $\mathrm{~b}_{\mathrm{b}}$ & \multirow[b]{2}{*}{$\mathrm{t}_{\mathrm{tr}}, \mathrm{s}$} & $b_{o}$, & $b_{b}$ & \multirow[b]{2}{*}{$\mathrm{t}_{\mathrm{tr}} \mathrm{s}$} & $b_{0}$ & $b_{b}$ \\
\hline & & & \multicolumn{2}{|c|}{$\begin{array}{l}\mathrm{N} \mathrm{s} / \mathrm{mm} \times \\
\times 10^{3}\end{array}$} & & \multicolumn{2}{|c|}{$\begin{array}{l}\mathrm{N} \mathrm{s} / \mathrm{mm} \times \\
\times 10^{3}\end{array}$} & & \multicolumn{2}{|c|}{$\begin{array}{l}\mathrm{N} \mathrm{s} / \mathrm{mm} \succ \\
\quad \times 10^{3}\end{array}$} \\
\hline 1 & 15 & 1.98 & 3 & 0.25 & 0.35 & 45 & 1.0 & 0.31 & 45 & 1.0 \\
\hline 2 & 70 & 0.53 & 45 & 1.00 & 0.43 & 45 & 1.0 & 0.35 & 45 & 1.2 \\
\hline 3 & 96 & 0.54 & 45 & 0.60 & 0.39 & 45 & 1.2 & 0.36 & 45 & 1.2 \\
\hline
\end{tabular}

The optimal stiffness value of the supports $k_{o}$ in all experiments is equals to $2 \mathrm{~N} / \mathrm{mm}$. In this, the quality functional may differ from the corresponding values in Table 2 by $3-10$ times under the limiting values of the parameter $b_{b}$ $\left(b_{b}=510^{-5} \mathrm{~N} \mathrm{~s} / \mathrm{mm}\right.$ and $\left.b_{b}=1.510^{-3} \mathrm{~N} \mathrm{~s} / \mathrm{mm}\right)$.

From the obtained results, it follows that:

1. The proposed methods $[25,26]$ of optimizing the parameters of the centrifugal juicer are also efficient under the impulse change of an unbalance at the rotor cruising velocity.

2. The stiffness of the supports does not practically affect the least value of the duration of transition processes. This is due to the fact that the stiffness of the supports mainly affects the frequency of free oscillations of the case and has almost no effect on the damping rate of these oscillations.

3. The optimal value of the viscosity of the supports of the centrifugal juicer is the same for almost all performed experiments and is equal to $0.045 \mathrm{~N} \mathrm{~s} / \mathrm{mm}$. The case of only the two-ball auto-balancer and the small unbalance is the exception, where the optimal value is equal to $0.003 \mathrm{~N} \mathrm{~s} / \mathrm{mm}$. This is due to the fact that under the small unbalance and high viscosity of the supports, the balls need more time to "feel" the change of an unbalance.

4. Auto-balancing comes faster with an increase of the number of the balls in an auto-balancer under any magnitude of an unbalance.

5. The optimal value of the coefficient of viscous resistance forces that prevent the relative motion of the balls; does not decrease with increasing the number of the balls and the magnitude of the sieve unbalance (for 3 and 4 balls).
6. The absolutely largest duration of transition processes is achieved under the small number of the balls ( 2 balls) in an auto-balancer and the small unbalance.

7. The absolutely smallest duration of transition processes is achieved under the large number of the balls ( 4 balls) in an auto-balancer and the small unbalance. To determine the coefficient of viscous resistance forces of the relative motion of the balls, which is the best for the entire interval of change of the sieve unbalance, an additional experiment is carried out:

$$
\mathrm{t}_{\mathrm{tr}}=\mathrm{f}\left(\mathrm{F}_{\max }, \mathrm{n}, \mathrm{b}_{\mathrm{b}}\right)=\mathrm{f}(15,4,0.0012)=0.34 \mathrm{~s} .
$$

From the latter it follows; that the auto-balancer with 4 balls and the coefficient of viscous resistance forces of the relative motion of the balls $b_{b}=0.0012 \mathrm{~N} \mathrm{~s} / \mathrm{mm}$ is the best option of an auto-balancer for balancing the centrifugal juicer on the entire range of the change of an unbalance. In this, the duration of transition processes changes from $0.34 \mathrm{~s}$ to $0.36 \mathrm{~s}$.

8. The case of a two-ball auto-balancer is the most "unstable" in relation to the change in the magnitude of an unbalance:

- the minimal values of the quality functional, which correspond to small and large unbalances, differ by 4 times;

- in this, the optimal values of the coefficient of viscous resistance forces of supports and the relative motion of the balls differ by 15 times and 4 times, respectively.

\section{3. Investigation of the influence of the radius of the} auto-balancer running track on the duration of transition processes (experiment 2)

For experiment 2, another auto-balancer is designed, for which the radius of the running track is equal to $R=51.34 \mathrm{~mm}$. The results of optimizing the duration of transition processes are given in Table 3 (the results of virtual experiments and also statistical analysis are not inducted). There is also no optimal value of stiffness of supports $\left(\mathrm{k}_{\mathrm{o}}=2 \mathrm{~N} / \mathrm{mm}\right.$ in all experiments).

Table 3

The results of optimization of the duration of transition processes under a fixed number of the balls and the balancing capacity of the auto-balancer

\begin{tabular}{|c|c|c|c|c|c|c|c|c|c|c|}
\hline \multirow{4}{*}{ No. } & \multirow{4}{*}{$\mathrm{F}_{\max }, \mathrm{N}$} & \multicolumn{9}{|c|}{$\mathrm{R}, \mathrm{mm}$} \\
\hline & & \multicolumn{3}{|c|}{31.86} & \multicolumn{3}{|c|}{41.6} & \multicolumn{3}{|c|}{51.34} \\
\hline & & \multirow[b]{2}{*}{$\mathrm{t}_{\mathrm{tr}}, \mathrm{s}$} & $b_{o}$ & $b_{b}$ & \multirow[b]{2}{*}{$\mathrm{t}_{\mathrm{tr}}, \mathrm{s}$} & $b_{o}$ & $b_{b}$ & \multirow[b]{2}{*}{$\mathrm{t}_{\mathrm{tr}}, \mathrm{s}$} & $b_{o}$ & $b_{b}$ \\
\hline & & & \multicolumn{2}{|c|}{$\begin{array}{l}\mathrm{N} \mathrm{s} / \mathrm{mm} \times \\
\times 10^{3}\end{array}$} & & \multicolumn{2}{|c|}{$\begin{array}{l}\mathrm{N} \mathrm{s} / \mathrm{mm} \times \\
\times 10^{3}\end{array}$} & & \multicolumn{2}{|c|}{$\begin{array}{l}\mathrm{N} \mathrm{s} / \mathrm{mm} \times \\
\quad \times 10^{3}\end{array}$} \\
\hline 1 & 15 & 0.31 & 45 & 1.0 & 0.34 & 45 & 0.6 & 0.38 & 45 & 0.35 \\
\hline 2 & 70 & 0.35 & 45 & 1.2 & 0.49 & 45 & 0.37 & 0.54 & 45 & 0.26 \\
\hline 3 & 96 & 0.36 & 45 & 1.2 & 0.60 & 45 & 0.37 & 0.64 & 45 & 0.19 \\
\hline
\end{tabular}

From the obtained results, it follows that:

1. The stiffness of the supports does not practically affect the lowest value of the duration of transition processes, as in experiment 1 .

2. The duration of transition processes decreases when decreasing the radius of the running track.

3 . The optimal value of viscous resistance forces of the relative motion of the balls decreases when increasing the radius of the running track. 
4. The absolutely smallest duration of transition processes is achieved under a small unbalance $\left(\mathrm{F}_{\max }=15 \mathrm{~N}\right)$ and a small radius of the auto-balancer running track $(\mathrm{R}=31.86 \mathrm{~mm})$.

5 . The largest duration of transition processes is achieved under a large unbalance $\left(\mathrm{F}_{\max }=96 \mathrm{~N}\right)$ and a large radius of the auto-balancer running track $(\mathrm{R}=51.34 \mathrm{~mm})$.

\section{Discussion of the research results about the auto-balancing process of the centrifugal juicer under the impulse change of an unbalance by $3 \mathrm{D}$ modeling}

1. Classification of the most unfavorable changes of an unbalance is carried out. The main ones are the rotations of the unbalance vector around the rotation axis of a rotor by:

$-90^{\circ}$ in the case of small unbalances (and the centers of two balls on the steady motion form the central angle greater than $90^{\circ}$ ), in this, each ball moves along the running track by $90^{\circ}$;

$-180^{\circ}$ in the case of medium and large unbalances (and the centers of two balls on the steady motion form the central angle less than $90^{\circ}$ ), in this, each ball moves along the running track by the angle from $180^{\circ}-\alpha$ to $180^{\circ}-\gamma$.

2 . From the results of experiments 1 and 2 , it follows that the proposed methods [25, 26] for minimizing the duration of transition processes, which is validated by the run-up of the centrifugal juicer under the fixed unbalance, are also effective in the case of the impulse change of an unbalance at cruising velocity.

3 . The increase of the number of the balls in an autobalancer under any magnitude of an unbalance leads to the decrease of the duration of transition processes. This is explained by the fact that:

- when there are $n(n>2)$ balls in the auto-balancer, the (n-2)-parameter family of the steady motions appears in the rotor machine;

- under the change of an unbalance, the balls make the transition between the two nearest steady motions.

The best option of the auto-balancer for balancing the centrifugal juicer on the entire range of the change of an unbalance is the auto-balancer with 4 balls and the coefficient of viscous resistance forces of the relative movement of the balls $b_{b}=0.0012 \mathrm{~N} \mathrm{~s} / \mathrm{mm}$.

The increase of the radius of the running track (under the same number of the balls and the balancing capacity of an auto-balancer) leads to the increase of the duration of transition processes. This is explained by the fact that the running track becomes less filled, and the balls need to make larger linear movements at the transition to the next steady motion.

Thus, the previously obtained theoretical results [23] about the influence of the number of correction weights in the auto-balancer and the radius of the auto-balancer running track on the duration of transition processes are confirmed.

From Table 2, it follows that the use of the two-ball auto-balancer is extremely ineffective during auto-balancing of the impulse change of an unbalance at cruising velocity. In this, the optimal values of the parameters and the smallest value of the functional strongly depend on the magnitude of an unbalance. These values may differ by several times (from 4 to 15 times). This is explained by the fact (except for what was said in paragraph 4) that the two-ball auto-balancer almost does not "feel" small unbalances.
While in the cases of the three-ball and four-ball autobalancers, the same values are the constants or differ by no more than $20 \%$.

The latter confirms the previously obtained theoretical and experimental results about the significant drawbacks of using two-ball auto-balancers. Therefore, it is not recommended to use two-ball auto-balancers, both in theoretical and experimental studies of transition processes that occur in auto-balancing of the rotor machines.

4. When comparing the obtained results of optimizing the parameters of an auto-balancer and the centrifugal juicer with the corresponding results of the work [26], obtained for run-up of the centrifugal juicer with the fixed unbalance, it follows that:

- the optimal values of the coefficients of stiffness $\left(\mathrm{k}_{\mathrm{o}}\right)$ and viscosity $\left(\mathrm{b}_{\mathrm{o}}\right)$ of the supports in both works practically coincide (the difference does not exceed $10 \%$ );

- the optimal values of the coefficient of viscous resistance forces of the relative motion of the balls $\left(b_{b}\right)$, obtained in [26], are smaller than the corresponding values of this work by $30-50 \%$; this is explained by the fact that the runup time ( $2 \mathrm{~s})$ is much longer than the duration of the impulse change of an unbalance $(0.05 \mathrm{~s})$;

- the trends in the influence of the running track radius of the auto-balancer and the number of the balls in the auto-balancer on the duration of transition processes are the same as in [26].

The obtained results can be used:

- when designing the auto-balancers for balancing on the move of machines with fast-rotating rotors;

- to improve the efficiency of auto-balancing of the centrifugal juicer during its operation.

The main drawback of the conducted studies is the possibility of using the obtained results only for static balancing of rotor machines by the ball auto-balancers. However, this drawback is compensated by the fact that the ball auto-balancers are used for auto-balancing in most cases.

In the future, similar studies are planned for other types of rotor machines.

\section{Conclusions}

3D modeling is the effective method for optimizing the parameters of the rotor machine with an auto-balancer under the impulse change of an unbalance. In the process of research, the following is established.

1. Classification of the most unfavorable changes of an unbalance is carried out. In particular, for the two-ball autobalancer, it has been found; that the unbalance turns by $90^{\circ}$ and $180^{\circ}$ around the rotation axis of the rotor are the most unfavorable.

2. It is shown that the methods proposed in previous works for the parameters optimization of the centrifugal juicer are also efficient in the case of minimizing the duration of transition processes under the impulse change of an unbalance at cruising velocity.

3 . The effect of the auto-balancer parameters on the duration of transition processes is studied. The previously obtained theoretical results that the increase of the number of the balls and the decrease of the radius of the running track lead to the decrease of the duration of transition pro- 
cesses are confirmed. The dependence of the optimal values of the parameters of the centrifugal juicer and the auto-balancer on the magnitude of an unbalance is revealed. The dependence is significant only for the two-ball auto-balancer and weakens with the increase of the number of the balls in the auto-balancer. It is not recommended to use two-ball auto-balancers in practice, in theoretical and experimental studies of transition processes.

4. It is established that at the centrifugal juicer run-up with the fixed unbalance and under the impulse change of its unbalance at cruising velocity:
- the trends in the influence of the running track radius of an auto-balancer and the number of the balls on the duration of transition processes are identical;

- almost all the corresponding optimal values of the parameters of the auto-balancer and the centrifugal juicer (except for the coefficient of viscous resistance forces of the relative motion of the balls) coincide;

- the optimal values of the coefficient of viscous resistance forces of the relative motion of the balls at run-up are less than the corresponding values under the impulse change of an unbalance by $35-50 \%$.

\section{References}

1. Thearle, E. L. Automatic dynamic balancers Part 2 - Ring, pendulum and ball balancers [Text] / E. L. Thearle // Machine Design. 1950. - Vol. 22, Issue 10. - P. 103-106.

2. Gusarov, A. Avtobalansirujushhie ustrojstva prjamogo dejstvija [Auto-balancers direct action devices] [Text] / A. Gusarov. Moscow: Nauka, 2002. - 119 p.

3. Filimonikhin, G. Zrivnovazhennya i vibrozakhist rotoriv avtobalansiramy z tverdimi koriguvalnimi vantazhami [Balancing and protection from vibrations of rotors by autobalancers with rigid corrective weights] [Text] / G. Filimonikhin. - Kirovohrad: KNTU, 2004. $-352 \mathrm{p}$.

4. Filimonikhina, I. I. Conditions for balancing a rotating body in an isolated system with automatic balancers [Text] / I. I. Filimonikhina, G. B. Filimonikhin // International Applied Mechanics. - 2007. - Vol. 43, Issue 11. - P. 1276-1282. doi: 10.1007/s10778-007-0132-5

5. Filimonikhin, G. Empirical criterion for the occurrence of auto-balancing and its application for axisymmetric rotor with a fixed point and isotropic elastic support [Text] / G. Filimonikhin, I. Filimonikhina, K. Dumenko, M. Lichuk // Eastern-European Journal of Enterprise Technologies. - 2016. - Vol. 5, Issue 7 (83). - P. 11-18. doi: 10.15587/1729-4061.2016.79970

6. Filimonikhin, G. Application of the empirical criterion for the occurrence of auto-balancing for axisymmetric rotor on two isotropic elastic supports [Text] / G. Filimonikhin, I. Filimonikhina, M. Yakymenko, S. Yakimenko // Eastern-European Journal of Enterprise Technologies. - 2017. - Vol. 2, Issue 7 (86). - P. 51-58. DOI: 10.15587/1729-4061.2017.96622

7. Filimonikhin, G. B. Investigation of the possibility of balancing aerodynamic imbalance of the impeller of the axial fan by correction of masses [Text] / G. B. Filimonikhin, L. S. Olijnichenko // Eastern-European Journal of Enterprise Technologies. - 2015. - Vol. 5, Issue 7 (77). - P. 30-35. doi: 10.15587/1729-4061.2015.51195

8. Nesterenko, V. Avtomaticheskaya balansirovka rotorov priborov i mashin so mnogimi stepenyami svobody [Automatic rotor balancing devices and machines with many degrees of freedom] [Text] / V. Nesterenko. - Tomsk: Izd-vo Tomsk. un-ta, 1985. - 84 p.

9. Sperling, L. Single-Plain Auto-Balancing of Rigid Rotors [Text] / L. Sperling, B. Ryzhik, H. Duckstein // Technische Mechanik. 2004. - Vol. 24, Issue 1. - P. 1-24.

10. Sperling, L. Two-plain automatic balancing [Text] / L. Sperling, B. Ryzhik, H. Duckstein // Machine Dynamics Problems. - 2001. Vol. 25, Issue 3/4. - P. 139-152.

11. Rodrigues, D. J. Two-plane automatic balancing: A symmetry breaking analysis [Text] / D. J. Rodrigues, A. R. Champneys, M. I. Friswell, R. E. Wilson // International Journal of Non-Linear Mechanics. - 2011. - Vol. 46, Issue 9. - P. 1139-1154. doi: 10.1016/j.ijnonlinmec.2011.04.033

12. Filimonikhin, G. Uravnoveshivanie avtobalansirom rotora v uprugo-vyazko zakreplennom korpuse s nepodvizhnoy tochkoy [Balancing auto balancer rotor in visco-elastic body fixed to a fixed point] [Text] / G. Filimonikhin, V. Goncharov // Bulletin of the Tomsk Polytechnic University. - 2014. - Vol. 325, Issue 2. - P. 41-49.

13. Gorbenko, A. Mass-Inertial Characteristics and Dimensionless Equations of Two-bearing Rotor Motion with Auto-balancer in Terms of Compensating Body Mass [Text] / A. Gorbenko // Science and Education of the Bauman MSTU. - 2015. - Issue 12. P. 266-294. doi: 10.7463/1215.0827773

14. Detinko, F. Ob ustoychivosti raboty avtobalansira dlya dinamicheskoy balansirovki [On the stability of work auto-balancer for dynamic balancing] [Text] / F. Detinko // Proceedings of the Academy of Sciences of the USSR. Meh. and machine building. 1956. - Issue 4. - P. 38-45.

15. Hsieh, H.-Y. Application of automatic balancers on a flexible-shaft rotor system [Text] / H.-Y. Hsieh, C.-J. Lu // The 22nd International Congress on Sound and Vibration. - 2015.

16. Majewski, T. Self-balancing system of the disk on an elastic shaft [Text] / T. Majewski, D. Szwedowicz, M. A. M. Melo // Journal of Sound and Vibration. - 2015. - Vol. 359. - P. 2-20. doi: 10.1016/j.jsv.2015.06.035

17. Goncharov, V. Studying the peculiarities of balancing of flexible double-support rotors by two passive automatic balancers placed near supports [Text] / V. Goncharov, G. Filimonikhin, K. Dumenko, M. Lychuk // Eastern-European Journal of Enterprise Technologies. - 2016. - Vol. 4, Issue 7 (82). - P. 4-9. doi: 10.15587/1729-4061.2016.75115 
18. Goncharov, V. Research of stability and transition processes of the flexible double-support rotor with auto-balancers near support [Text] / V. Goncharov, A. Nevdakha, Y. Nevdakha, V. Gutsul // Eastern-European Journal of Enterprise Technologies. - 2016. Vol. 6, Issue 7 (84). - P. 22-27. doi: 10.15587/1729-4061.2016.85461

19. Tadeusz, M. Position error occurrence in self balancers used on rigid rotors of rotating machinery [Text] / M. Tadeusz // Mechanism and Machine Theory. - 1988. - Vol. 23, Issue 1. - P. 71-78. doi: 10.1016/0094-114x(88)90011-0

20. Yang, Q. Study on the influence of friction in an automatic ball balancing system [Text] / Q. Yang, E.-H. Ong, J. Sun, G. Guo, S.-P. Lim // Journal of Sound and Vibration. - 2005. - Vol. 285, Issue 1-2. - P. 73-99. doi: 10.1016/j.jsv.2004.08.009

21. Sung, C. K. Influence of external excitations on ball positioning of an automatic balancer [Text] / C. K. Sung, T. C. Chan, C. P. Chao, C. H. Lu // Mechanism and Machine Theory. - 2013. - Vol. 69. - P. 115-126. doi: 10.1016/j.mechmachtheory.2013.05.009

22. Haidar, A. M. A general model for passive balancing of supercritical shafts with experimental validation of friction and collision effects [Text] / A. M. Haidar, J. L. Palacios // Journal of Sound and Vibration. - 2016. - Vol. 384. - P. 273-293. doi: 10.1016/ j.jsv.2016.08.023

23. Goncharov, V. An increase of the balancing capacity of ball or roller-type auto-balancers with reduction of time of achieving auto-balancing [Text] / V. Goncharov, G. Filimonikhin, A. Nevdakha, V. Pirogov // Eastern-European Journal of Enterprise Technologies. - 2017. - Vol. 1, Issue 7 (85). - P. 15-24. doi: 10.15587/1729-4061.2017.92834

24. Pat. No. 107022 UA. Elektrychna tsentryfuzhna napivavtomatychna sokovyzhymalka [Electric centrifugal juicer semiautomatic]. IPC G01M 1/32 [Text] / Filimonikhin G. B., Goncharov V. V.; the applicant and the patentee: Kirovograd National Technical University. - No. a201301212; declareted: 01.02.2013; published: 10.11.2014, Bul. No. 21.

25. Goncharov, V. Parameter optimization of $3 \mathrm{D}$ models of centrifugal juicer with auto-balancer by minimization of steady vibroacceleration [Text] / V. Goncharov, G. Filimonikhin // Eastern-European Journal of Enterprise Technologies. - 2014. - Vol. 1, Issue 7 (67). - P. 9-14. doi: 10.15587/1729-4061.2014.20678

26. Goncharov, V. Parameters optimization of centrifugal juicer with auto-balancer by minimization of time of autobalancing occurred [Text] / V. Goncharov, G. Filimonikhin // Eastern-European Journal of Enterprise Technologies. - 2014. - Vol. 2, Issue 7 (68). P. 28-32. doi: 10.15587/1729-4061.2014.23317

27. Olijnichenko, L. Optimization of parameters of autobalancers for dynamic balancing of impeller of axial fans by 3D modeling [Text] / L. Olijnichenko, G. Filimonikhin // Eastern-European Journal of Enterprise Technologies. - 2014. - Vol. 6, Issue 7 (72). P. 12-17. doi: 10.15587/1729-4061.2014.30498

28. Filimonikhin, G. Eksperymentalne vyznachennya efeknyvnosti dynamichnoho zrivnovazhennya kulevymy avtobalansyramy krylchatky ocevoho ventylatora [Experimental determination of the efficiency of dynamic balancing by ball-type auto-balancers of the impeller of axial fan] [Text] / G. Filimonikhin, L. Olijnichenko // Automation products. Machine build processes and instrument. - 2011. - Issue 45. - P. 496-502.

29. Olijnichenko, L. Experimental study of the process of the static and dynamic balancing of the axial fan impeller by ball auto-balancers [Text] / L. Olijnichenko, V. Goncharov, V. Sidei, O. Horpynchenko // Eastern-European Journal of Enterprise Technologies. 2017. - Vol. 2, Issue 1 (86). - P. 42-50. doi: 10.15587/1729-4061.2017.96374 